\title{
Evidence Based Service Policy in Libraries: The Reality of Digital Hybrids
}

\author{
Asiye Kakırman Yıldız \\ Department of Information and Records Management, Marmara University, Turkey
}

Copyright $(2016$ by authors, all rights reserved. Authors agree that this article remains permanently open access under the terms of the Creative Commons Attribution License 4.0 International License

\begin{abstract}
Evidence based library management is one of the most significant contemporary developments in professional library practice. Although they are non-profit making organisations, the main aim of libraries is to satisfy their customers, that is, the library users. This aim is achieved as long as the needs and expectations of the users are met. For this reason, the libraries must know their users very well and must provide a service which fulfils their needs and expectations. Therefore, rather than following fashionable or popular approaches which are discussed in the literature, libraries should carry out their own analyses and develop an evidence-based service policy for their users. In the studies made by Mark Prensky, individuals are classified and evaluated according to their technological abilities and skills into 2 groups as "digital natives" or "digital immigrants" and since this time the subject has continued to be discussed. According to Prensky, those born before 1980 should be classed as digital immigrants and those born after 1980 are classed as digital natives. The digital natives were literally born into a world of knowledge and technology. The most important characteristic of digital natives is that not only do they perform more than one function on a single device simultaneously. In this study it was analyzed that whether the students that study in the different faculties of Marmara University are digital natives or not. The study also examines how to user group of "digital hybrids" has an effect on the management procedures of the library and how this element affects the management of the other elements. The questionnaire that formed the basis of this study was applied to 382 students and their approach to accessing information was analysed. After the completion of the survey, a new category of "digital hybrids" was proposed; it is suggested that digital natives, who in the literature are described as those born after 1980, should in fact be defined as those born after the year 2000, digital immigrants should be defined as those born before 1970 and those between from 1970-1999 should be described as digital hybrids. The result of this study important that also, rather than the fashionable approaches in the literature, we need to consider the needs and expectations of the users; digital natives, digital immigrants or digital hybrids and to adopt an evidence-based approach to service policy development.
\end{abstract}

Keywords Evidence Based, Library Policy, Digital Natives, Digital Immigrants, Digital Hybrids

\section{Introduction}

The developments during the digitization process, hybrid structures that come forward with the use of both digital and printed publications, are also seen in the user groups of these libraries. Although in literature people born after 1980 and after are named digital natives, as you can see in the study below, on the contrary of what Prensky [1] suggests, it is seen that $80 \mathrm{~s}$ aside, even people born in 90s are not fully natives. In the study, it is seen that people born in 90 s use both digital and printed sources; just like the libraries that present both digital and printed sources, their user groups are also "hybrids".

Libraries that try to provide services taking into account of their users' (digital native / digital immigrant / digital hybrid) needs and expectations (will) experience the paradoxical situation of the corporate situation while they are trying to provide user satisfaction.

There are many studies that have been published on the information gathering habits and the approaches of the new generation, which is usually named as the "net generation", who have grown up with the digital media. In these studies, the studies of Marc Prensky are quite remarkable in which the individuals are divided into groups as digital natives and digital immigrants regarding their closeness to the digital media. In his study "Digital Natives Digital Immigrants" Prensky [2] mentions that the learning style of the students has radically changed and the teachers stayed as digital immigrants teaching the digital native students.

In his study is seen that Prensky has drawn the exact line between digital natives and digital immigrants. However, for the transition from a situation to another, which means during a transformation process, there needs to be a soft transition process line to prevent the shock. Especially in an applied science such as librarianship, it is known that nothing can be done in exact drawn lines and there is always a transition process. Thus, it is seen that even in our date, libraries keep printed sources while turning their 
collections into digital ones. Libraries that are referred to as "hybrids" are the result of this transition process.

Other than this, it is not ordinary for libraries that provide services and activities according to their user needs and expectation to suddenly change their system. That is why, while libraries offer both printed and digital sources to their users, there can't be an exact distinction between digital native library and digital immigrant library, the idea of distinct classification to call people born after 1980 digital natives and the ones born before that digital immigrants do not seem correct.

In Prensky's studies, it is seen that there is an approach based on the age in the categorization of digital natives and digital immigrants. In this extremely accurate approach, it is actually emphasized that technological proximity and age have a parallel relationship between them. However, Prensky is seen as if he is being unfair to people born before 1980 by calling them digital immigrants. As a matter of fact, according to Prensky, people born between 1970-1979 who are in their early $30 \mathrm{~s}$ and $40 \mathrm{~s}$ are also included in digital immigrants. But, it is seen that these age groups advantageously use the technology to make their works easier and it is seen that even if the paper use continues, tablet and computer usage increases.

In literature it is mentioned that digital immigrants use the printed sources and after that they use the digital sources [3]. However, the average age of these people are thought to be 45 and higher. As a matter of fact, in many studies done on different age scales, it is found that when there is a need to find information about something, the first place they look is Google [4]. That is why the categorization of the age groups should be redefined.

The ideas of Prensky on new generation using digital devices and their habits on these are true without doubt. However, it is thought that the age group that has the ability to do that is the ones born in 2000 and after who are also called the Millenium Age Generation. That is why naming those who are born in 2000 and after the digital natives will be more correct and realistic.

Apart from this, it is knowns that the ones who are born after 1970 have also control over technology, just like that new generations they use the internet for information, they can read and listen to music at the same time and text through their cell phones. However, it is also seen that the same group does not stop using printed sources. As it can be seen in the figure below, it is appropriate to name those who are born between 1970 - 1999 as "digital hybrids".

\section{Materials and Methods}

\subsection{What is the Evidence-based Approach?}

For an institution, this means that evidence, data and results are collected in systematic and controlled manner and this data is used in the process of formulating the service policy of that institution. The institution examines these findings using its own equipment and expertise, analyses and synthesis the results and evaluates the situation, the procedures and service results. The evidence-based approach is quite a new concept in the literature of management. In fact, the idea is quite simple: to find the best evidence that can be found, to work on that evidence and then to meet the needs identified by the evidence without paying attention to what has been said or written before or to what is recommended by fashionable management gurus [5]. Libraries generally know the importance of collecting and using data, both in the planning process and in the decision-making process but they tend not to make use of it in a systematic and effective way. This is because they are general trends of the market and, instead of working on evidence and drawing up a new roadmap, they try to apply one of the previously existing roadmaps to their own situation. However, as each institutional library has its own unique conditions and group of users, no fixed set of recommendations will exactly meet special conditions and needs of that library [6]. For example, the user group of university libraries consists of university students, academics, administrative personnel and independent researchers from outside the institution. This is so in all over the world. However, no library exactly resembles another from the aspects of management structure, budget and user-profile. Consequently, even if the problems generally tend to be the same, a solution which fits one particular library may not necessarily fit another. This is because each library has its own special conditions and user group. Evidence-based applications, which first began in the field of medicine, towards the end of the 1990s were increasingly applied to the fields of social science, human resources, business management and other similar disciplines. Practical sciences such as librarianship, the fundamental problem of which is the difference between theory and practice, attempt to bridge the gap by means of evidence-based applications [7]. It can be observed that many definitions of evidence-based applications have been made in the literature. The most generally known of these definitions in this definition by Booth [8]: data is collected from certain particular sources, a reliable and consistent model is developed using the available sources and decisions are made and applications applied using this model. Booth also states that in order to develop evidence-based applications it is necessary to collect the data using very detailed pre-prepared forms and surveys.

\subsection{Digital Hybrids and Their Characteristics}

Digital hybrids both resemble digital natives and also do not resemble the. These hybrids, while trying to make use of all the technological resources, nevertheless do not use them in the same effective and active manner as do the digital natives. It is known that there is almost no person left without a computer. Consequently, those who were born after the year 2000 were born surrounded by technology. 


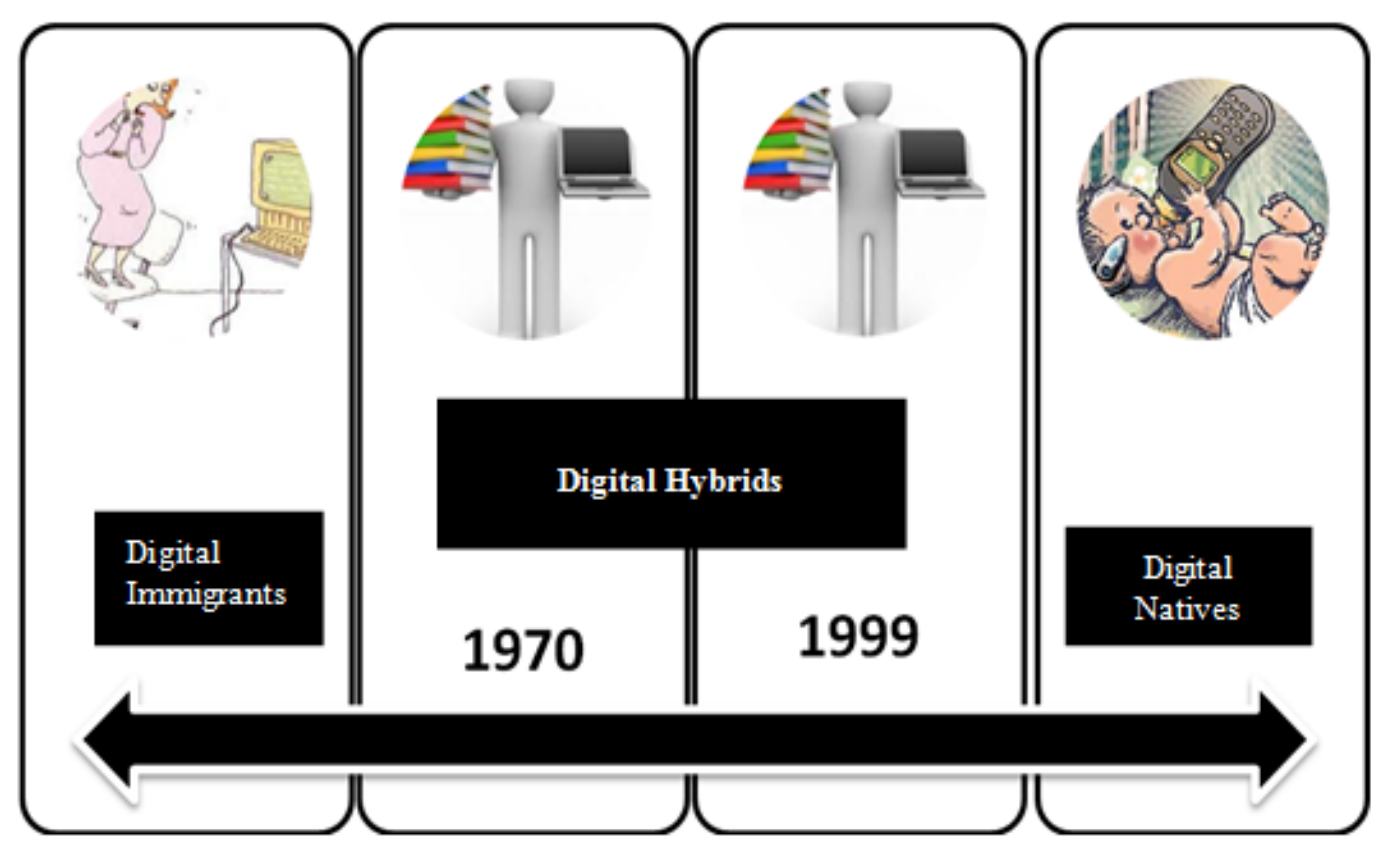

Figure 1. Digital immigrant to digital natives

In the literature, digital immigrants to learn, first look at print resources, and then search the Internet [9]. The opposite is stated about the digital natives. Digital hybrids combine the behavior of these two groups. In other words, the printed sources of digital technology are also extremely important for hybrids. Both are essential. However, Google is usually the first place they look. The big gap between digital natives and digital immigrants, as mentioned in the work of Prensky, is very large. However, in order for such a large gap to exist, there is no need for the age difference to be very great or for the living environment to have changed radically. Also, it is not possible to draw a very definite dividing line. Thus the digital hybrids, who show that there is an intermediate phase linking these two extremes, are the group who are preparing themselves, or trying to prepare themselves, for the new age. Unlike the digital hybrids, the digital immigrants have not been able to get used to this change or, in other words, have remained on the other side of the chasm. The digital natives, on the other hand, have not had to get used to anything because they were born and grew up right in the middle of a ready-made technological environment. For this reason, the digital natives had no other alternative.

\subsection{The Scope of the Study}

This study has been applied to students from different departments and faculties in first and second grades in Marmara University. Marmara University continues its educational activities, being one of the prominent universities in Turkey, with around 3000 lecturers and 60.000 students. The population is the students of Göztepe Campus of Marmara University; sampling group was determined by one of the classification techniques of probability, probability sampling method and one of the types of this method, simple random sampling way.

\subsection{The Aim of This Study}

In this study, it was intended to examine if Mark Prensky's digital native group is actually native or not; and if they show native digital behaviours or not. As a result of this examination, it was intended to determine the characteristics of the group that needs to be referenced while creating service policies of libraries.

\subsection{Defining the Problem}

In literature, the intended age categories by digital natives and digital immigrants needs to be taken as an issue again and it is thought that the library users, just as the libraries that present published and digital materials together, are considered "hybrid". At this point, the questions that are needed to be asked are;

1. Just like that library structures, are the library users not supposed to have hybrid characteristics?

2. Users that do not stop using both printed and digital publications should be included in which category? Digital natives or digital immigrants?

\subsection{The Hypothesis of the Study}

Regarding the "It is doubted that Prensky's digital natives reference in 1980 and later is a correct classification and an evidence based approach is needed for determining service policies of libraries" hypothesis, the age categories of digital native and digital immigrants will be redefined and with the thought of like library structures, library user groups can have a hybrid structure, a term such as "digital 
hybrids" will be advised.

\section{The Interpretation of the Findings}

\subsection{Are They Digital Natives / Digital Hybrids / Digital Immigrants? : Results Of The Survey And Interpretation}

\subsubsection{Age Difference}

In this part of the study, it will be determined, according to the results of the survey, if the students who participated in the study are digital natives, digital immigrant or digital hybrids and results or the survey will be interpreted.

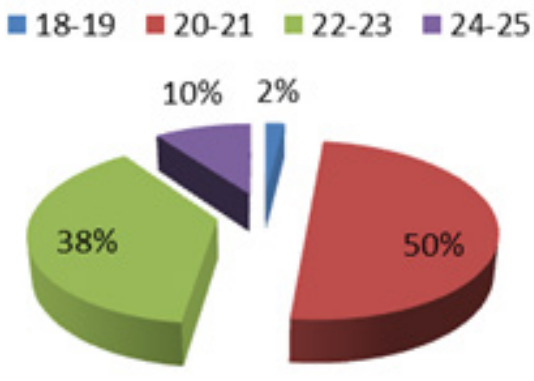

Graphic 1. Age difference

Half of the students who participated in the survey were aged 20-21. Therefore, it can be said that on average they were born in 1991. Those aged $18-19$ (that is, those born in 1994) made up 4\% and aged 24-25 made up 10\% (those born 1987). Therefore the students participating in the survey were born between 1987 and 1994 .

3.1.2. How many times in the last year did you physically use the library? (physically go to the library)
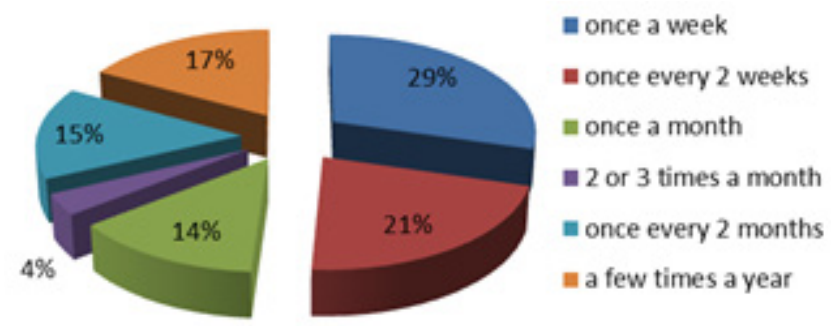

Graphic 2. Physical utilization of the library

It was seen that those physically using the library were not at all few. In fact, $30 \%$ of the students used the library once a week and $22 \%$ used it once every 2 weeks. Therefore, it would be true to say that the students, on average, used the library once every 10 days. The number using the library a few times a year was quite high at 34 . However, it would be wrong to assume that this means that they were using the digital environment. In fact, as we can see below, the number using the digital environment a few times a year was 21 . As the previous graph shows, those participating in the survey were born between 1991 and 1994. According to Prensky, a person born during this period should be a digital native. However, if we look at the results, we can see that they continued to physically use the library in some way.

3.1.3. How many times did you visit the library over the web to access information in the past year?

monce a week $\quad$ once every 2 weeks $=$ once a month
= 2 or 3 times a month $\mathbf{m}$ once every 2 months $\mathbf{m}$ a few times a year

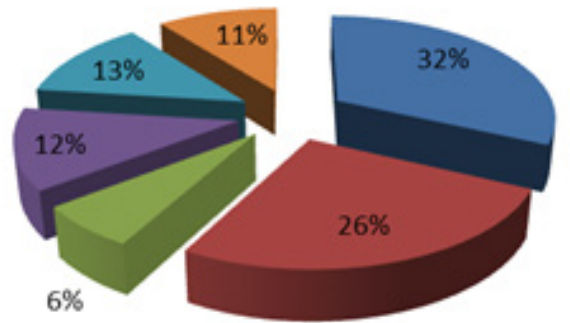

Graphic 3. On-line utilization of the library

It is expected that digital natives will not use the library building. In other words, it is claimed that digital natives do not use the library building. In other words, it is claimed that digital natives do not use the library physically. However, according to the results above, we can see that there appears not to be much difference between the numbers using it digitally. In fact, while $32 \%$ of the same group use the library physically. Also, while $26 \%$ of the students use the digital library once every 2 weeks, $22 \%$ use it physically once every 2 weeks. Of course, when we look at the average results, use of the digital library is higher overall than use of the library physically.

In an environment which is changing in parallel with technological developments, it is natural for relatively easy digital use to be higher than relatively trouble some physical use. Nevertheless, these results are important from the point of view of demonstrating that the students display the behaviour patterns of digital hybrids.

3.1.4. When I access sources in the digital environment;

$$
\begin{aligned}
& \text { I prefer to get a print out and read it } \\
& \text { I prefer to read it from the computer screen } \\
& \text { I do both of these things }
\end{aligned}
$$

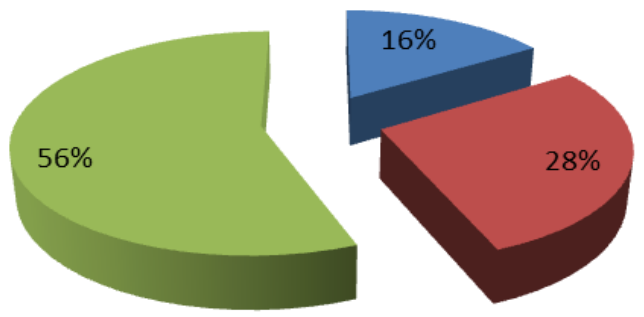

Graphic 4. Approach to digital environment

In the literature, it mentions that digital natives carry out searches in the electronic environment and can do several 
different things at the same time; the students who took part in the survey (answered the questionnaire) are in a situation which is similar to the situation of the libraries during the period when they were adapting to the process of digitalisation, and they display hybrid behaviour. The answers obtained in the survey suggest that the new generation are neither completely digital natives nor completely digital immigrants. a group of the students which we can describe as digital hybrids are both competent in technological knowledge and skills and also sometimes prefer traditional methods.

That $56 \%$ of the students who answered the questionnaire both access recorded information in the electronic environment and also like to receive it in printed form is a sign of this. At the same time, it is interesting to observe that $16 \%$ of the students prefer only to read printouts, while $28 \%$ exclusively prefer to read material in the digital environment.

\subsubsection{What is the success rate of information gathering with on-line access?}

It is really surprising that $\% 12$ of the group named as digital natives by Prensky has never used the library by remote access. Thus, these numbers and rates do not comply with the definition of digital native. Apart from this, 90 of the students that have the ability to gather information with a remote access answered as \%60-70, and 75 with \%50-60. That's why, it is seen that 165 of 382 students have averagely $\% 60$ success rate; and 143 have $\% 70$ success rate. The number of students that see themselves $\% 100$ on remote information access is " 0 ".

$$
\begin{aligned}
& =\% 10-20 \\
& =\% 20-30 \\
& =\% 30-40 \\
& =\% 40-50 \\
& =\% 50-60 \\
& =\% 60-70 \\
& =\% 70-80 \\
& =\% 80-90 \\
& =\% 90-100
\end{aligned}
$$

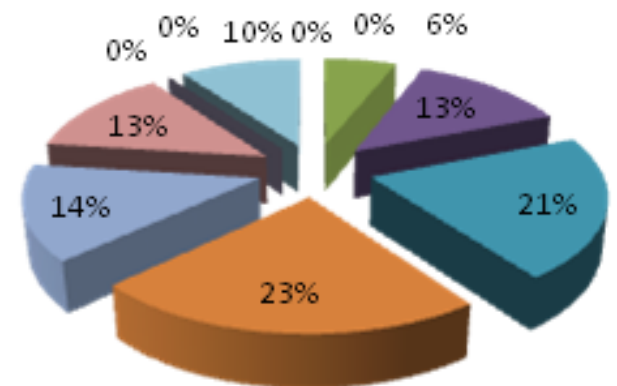

Graphic 5. Success of on-line information gathering

\subsubsection{What is the success rate of gathering information from printed publications?}

As an evidence to show that Prensky's digital native group is actually a digital hybrids group, the results above can be shown. While the number of students of digital information gathering is 0 , the $\% 100$ rate of information gathering from printed publications is $23(\% 6)$. This number is of course low; however, when it is compared to digital information gathering it is important to show the hybrid characteristics of this age group. Having a disorganized scale, this result shows that 186 of these students see themselves $\% 80$ successful in information gathering through printed publications which is a rather high ratio compared to information gathering through remote access. That is why, it is seen that more than the half of the students are more successful in gathering information through printed publications than the remote access. This result does not mean that they use digital environment less or stay away from it. However, it proved that they are hybrids once again.

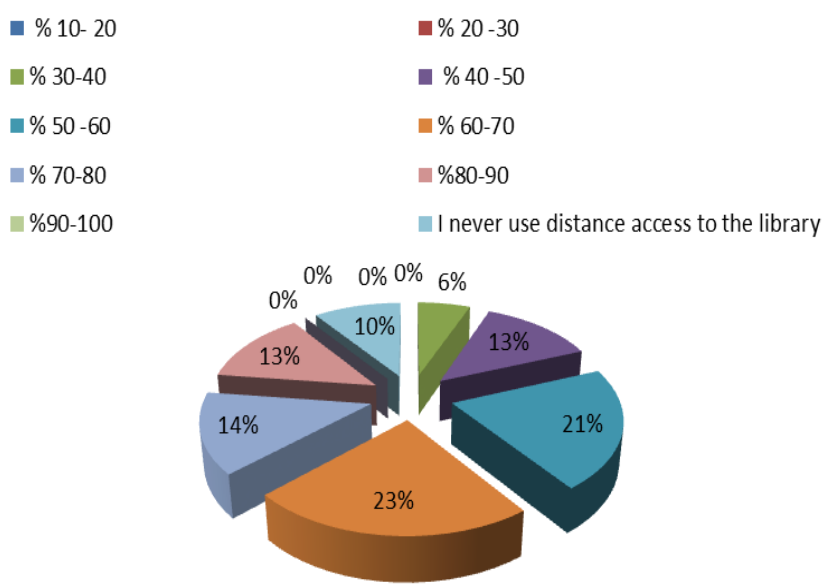

Graphic 6. Success of printed information gathering

\section{Conclusions}

This study has found that management of libraries rather than the fashionable approaches in the literature, we need to consider the needs and expectations of the users; digital natives, digital immigrants or digital hybrids and to adopt an evidence-based approach to service policy development.

Library managers need to consider and plan for practical steps that could be taken to introduce the concept of evidence based practice in their decision-making processs. EBLM is one of the most significant developments in professional library practice. Particularly in university libraries, it should be stressed that to meet the information needs of students, academic staff and researchers more evidence-based studies are needed. For this reason, it is very important that there should be a culture of self-evaluation in libraries and that such a culture should be encouraged, both for the institutionalisation of the library personnel. If there is no culture of self-evaluation in a library, then the user-group will not be systematically analysed and if the users are not properly defined, their needs and expectations will not be met, which will create dissatisfaction among them.

Library managers will have to be able to learn to change from a culture of institution-based decision making to a evidence-based decision based on analytics and concrete results. Above all, they need to cultivate a culture of reflective practice, continually questioning what they do, regardless of whether the stimulus is published research, user 
feedback or their own professional observations.

Therefore, libraries should serve their user-groups according to their needs. If a university library which looks upon its users as digital natives in line with Prensky's theory has users who display hybrid behaviours, it will create a wrong service policy. For example, if a library categorises its users as digital natives in accordance with Prensky's ideas and creates a service policy in accordance with these ideas and doesn't correctly analyse the needs of the users the result will be a wrong service policy. On the other hand, if a study is conducted among the users and their profile is correctly known, it will be seen that the users are not completely "digital" or completely "native" but are, in fact "digital hybrids".

As well as in their collections, a hybrid structure is seen in the user groups of libraries. As can be seen from this study, the group of users born after 1990, the digital hybrid group, display patterns of behaviour which conform with the present structure of libraries. Actually this approach shows a parallel situation to the services provided by the libraries at present. In conclusion, the existing situation is that the libraries do not and can not offer a service which consist purely of printed material or purely of digital material. In consequence, we can say that the present state of the libraries reflects the characteristics of the user group at the present time.

In contrast to what is claimed by Prensky, it seems therefore that it would be more accurate to classify those born after the year 2000 as digital natives, rather than those born after 1980. In fact, it appears as if the children of the milennium could more accurately be described as such. Those born between 1970 and the year 1999 seem to be a group who, in spite of using electronic materials are not willing to give up using traditional printed materials. To be more exact, they are ones who are constitutionally".

\section{REFERENCES}

[1] M. Prensky, Digital natives, digital immigrants, Part II: Do they really think differently? On the Horizon 9 (6), 1-6. Accessed on 13 May 2012 at http://d.scribd.com.docs/25yf w2gwramobijnk3vt.pdf

[2] M. Prensky, Digital natives, digital immigrants. On The Horizon. 9 (5): 1-6. Accessed on 13 May 2012 at http://www.marcprensky.com/writing/ Prensky\% 20\%20 Digital\%Natives, \%20Digital\%20 Immigrants \%20-\%20Part 1.pdf

[3] J. Palfrey, ve U. Gasser, Born digital: Understanding the first generation of digital natives. NewYork, NY, USA: Basic Books, 2010.

[4] P.Nunez-Gomez, Trends in the social an interpersonal relations of young people and digital natives in the Web 2.0. Revista Latina de Communicación Social www.revistalatina cs.org

[5] A. Lakos, Evidence- Based Library Management: The Leadership Challenge, Portal: Libraries and Academy, vol. 7, number. 4, 431-450, 2007

[6] A. Kakırman Y1ldız, Evidence-Based Library Management as a New Concept for Decision Makers: A Case Study in Turkey. IFLA 2012 Satellite Meeting, 8-9 August, Turku, Finland .http://kirjasto3.utu.fi/ifla2012/abstracts/KakirmanYi ldiz_abstr.pdf

[7] A. Booth, Bridging the research - practice gap? The role of evidence based librarianship", New Review of information and Library Research, 9,1:3-23, 2003.

[8] A. Booth and A. Brice, "Appraising the Evidence", Evidence-Based Practice for Information Professionals $a$ Handbook Ed. Facet Publishing, London, 104-119.

[9] M. Prensky, Digital natives, digital immigrants, Part II: Do they really think differently? On the Horizon 9 (6), 1-6. Accessed on 13 May 2012 at http://d.scribd.com.docs/ 25yfw2gwramobijnk3vt.pdf 